Journal of Engineering and Applied Sciences 15 (2): 602-606, 2020

ISSN: 1816-949X

(C) Medwell Journals, 2020

\title{
Statistical Forecasting of Petrol Price in South Africa
}

\author{
Matthew Femi Olayiwola and Solly Matshonisa Seeletse \\ Department of Statistics and Operations Research, Sefako Makgatho Health Sciences University, \\ Molotlegi Street, Ga-Rankuwa, South Africa
}

\begin{abstract}
This study focuses on the commercial patterns of petrol price in South Africa. Its aim is to determine the continuity of past patterns of the petrol price series into the future using time series techniques. About 14 years monthly-based retail fuel prices of unleaded 95 petrol were collected from the Department of Energy, South Africa. Price settings on consumer goods are used for economic growth. On the other hand, sudden price fluctuations inconvenience consumers. Also, price increases reduce disposable cash for the consumers. These patterns reduce wealth and for the average consumer they may lead to poverty. The study results show that in South Africa, the upward trend variation continues into the future petrol price in a quadratic rate while there are also some indications of seasonality of petrol price.
\end{abstract}

Key words: Autocorrelation function, correlogram, fuel price, stationarity, economic growth, South Africa

\section{INTRODUCTION}

Countries regulate their economies by putting laws to regulate activities of the economy. One such control is fuel regulation. In South Africa, the South African government controls wholesale margins and controls the retail price of petrol through the Department of Energy (South Africa, 2008, Anonymous, 2008, 2009). The laws are determined in line with countries that exchange trade on same matters. South Africa trades with Europe and the USA, among other nations. Hence, the price of petrol in South Africa is associated with the price of petrol in US dollars in certain international petrol markets.

The South Africa Yearbook (2008/09) explains that this pattern of associations is an indication that the domestic price is also influenced by supply and demand for petroleum products in international markets as well as by with the rand/dollar exchange rate.

The fundamental philosophy for the foundation for establishing the Basic Fuels Price (BFP) is to represent realistic, market-related costs of importing a considerable quota of South Africa's liquid fuels supplies (Mondliwa and Roberts, 2014). Therefore, such supplies are obtained from overseas refining centres that can satisfy South Africa's requirements of product quality and sustainable supply considerations.

The import parity BFP principle is a well-designed, complete method of BFP determination to ensure that local refineries compete with their international counterparts. This promotes cost-effectiveness and intelligent rough acquisition strategies to ensure survival in a volatile and competitive international environment. As a result, this leads to elimination of domestic inflationary pressures.
The BFP of petrol, diesel and illuminating paraffin is calculated on a daily basis. These daily calculations are either higher or lower than the BFP values reflected in the fuel price structures at that time. If the daily BFP is higher than the BFP in the fuel prices, a unit under recovery is realised on that day. When the BFP is lower than the BFP in the price structures, an over recovery is realised on that day. An under recovery therefore, refers to when fuel consumers are paying less for a product on that day.

On the other hand, in an over recovery situation, consumer are paying more for product on that day. These calculations are done for each day in the fuel price review period and an average for the fuel price review period is calculated. This monthly unit over/under recovery is multiplied by the volumes sold locally in that month.

The cumulative over/under recovery is recorded on a cumulative over/under recovery account (referred to as the "Slate account"). A Slate levy is applicable on fuels to finance the balance in the Slate account when the Slate is in a negative balance (Lloyd, 2001).

This study focuses on determining the continuity of commercial patterns of the petrol price into the future by first decomposing the series and then forecast for short-term period. Therefore, this study uses time series techniques.

Time series procedure: A common approach to examine a regular time series occurs by use of a line chart, also known as the time plot. Generally and for most time series data, this plot exposes the nature of the trend immediately and can also reveal the absence of a trend. Also, when the time series are arranged in a convenient

Corresponding Author: Solly Matshonisa Seeletse, Department of Statistics and Operations Research, Sefako Makgatho Health Sciences University, Molotlegi Street, Ga-Rankuwa, South Africa 
way for detecting seasonality patterns, this plot reveals the nature of seasonality in a clear fashion. For superior results of these analyses, modern statistical practices dictate use of statistical packages and spreadsheets.

The advantage of using spreadsheets is that once, the suitable time period is chosen, the calculation of change over the periods can be easily done and with required levels of accuracy. The nature of the trend can be easily revealed as well as the type of seasonality. When planning, trend assists in preparing resources according to the future requirements. For instance, petrol price increase compels vehicle owners to prepare more cash for the future. Seasonality assists also in planning. During high seasons of price of petrol, vehicle owners reserve more cash while during low seasons they prepare less cash.

Other time series analysis techniques mentioned by various time series practitioners (Nikolic et al., 2012) include:

- Autocorrelation analysis to examine serial dependence

- Spectral analysis is used to examine cyclic behaviour which need not be related to seasonality

A time series is easily described and comprehensible when decomposed or separated into its basic components. The decomposition of time series is a statistical method that deconstructs a time series into notional components (Kantz and Schreiber, 2004). One of the main objectives for decomposition is to estimate seasonal effects that can be used to create and present seasonally adjusted values. These four components or characteristics movement of time series according to Enders (2003) are Trend component $\left(\mathrm{T}_{t}\right)$; Seasonal component $\left(\mathrm{S}_{\mathrm{t}}\right)$; Cyclical component $\left(\mathrm{C}_{\mathrm{t}}\right)$ and Irregular component $\left(\mathrm{I}_{\mathrm{t}}\right)$.

Forecasting entails formation of statistical models for stochastic simulation purposes in order to generate alternative versions of the time series, representing what might happen over non-specific time-periods in the future (Woodward et al., 2011). Therefore, the term 'forecasting' shall mean a scientific method for translating past experience into estimates of the future. Simple or fully formed statistical models are used to describe the likely outcome of the time series in the immediate future given knowledge of the most recent outcomes (Shasha and Zhu, 2004). This means that once a time series model is developed for forecasting purpose, it should be able to provide short term forecasts that give indications of the possible performance on medium (and maybe long term) forecasting.

In order to improve results of time series methods, suitable regression models may be added (Armstrong, 2012). This study benefits from this use as well.

\section{MATERIALS AND METHODS}

Monthly retail fuel price data were collected for the period of 14 years, specifically from years 2000-2013 from the Department of Energy of South Africa. The monthly petrol prices are considered as the time series, $\mathrm{y}_{\mathrm{t}}$ and months are considered to be time, tables were used to present the results obtained. Also, appropriate graphs were used to pictorially represent some of these values. In particular, time series plots were used to determine the components present in the series.

The original time series was decomposed accordingly using multiplicative model due to its clear trending pattern as additive would have suggested lack of trend. Measures of accuracy were also calculated for every different method of analysis in order to ensure reliability of results when finally adopting the most suitable forecasting method. All the data analyses were done using the MINITAB Software.

\section{RESULTS AND DISCUSSION}

Time series plot: The time series plot of original retail fuel price data shown in Fig. 1 shows that there is trend variation in the series, since, the mean of the series changes systematically with time. But there is no seasonal variation (i.e., identical or almost identical pattern which a time series appear to follow during corresponding month or quarter of successive years).

Trend estimation analysis: Table 1 shows the measures of accuracy values obtained based on different trend models.

The results of measures of accuracy in Table 1 for various trend models show that quadratic trend model is

Table 1: Measures of accuracy of different RFP trend models Trend models

\begin{tabular}{lrccr} 
& \multicolumn{2}{c}{ Trend models } & & \\
Variables & Linear & Quadratic & Exponential growth & S-curve \\
\hline MAPE & 13.29 & 7.48 & 7.66 & 8.61 \\
MAD & 79.22 & 50.25 & 50.67 & 60.05 \\
MSD & 8942.60 & 5397.60 & 5388.12 & 6670.63 \\
\hline
\end{tabular}

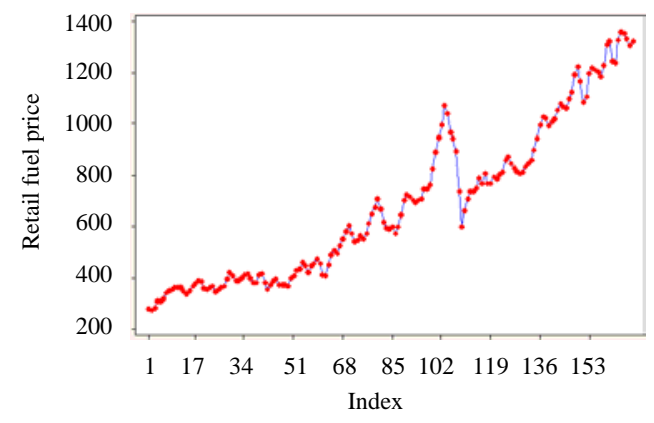

Fig. 1: Time series plot of retail fuel price 
the best model for the retail fuel price as it has least MAPE and MAD values of 7.48 and 50.25, respectively compared to the remaining models MAPE and MAD values. Thus, it is estimated below (Fig. 2).

Decomposition component analysis: Though there is no seasonal variation in the RFP series yet it was decomposed into various time series components. The seasonal indices values were obtained using the percentage moving average method. Its seasonal indices values were graphed in Fig. 3. Also, Fig. 4 is the graphical representation of decomposition component analysis of RFP.

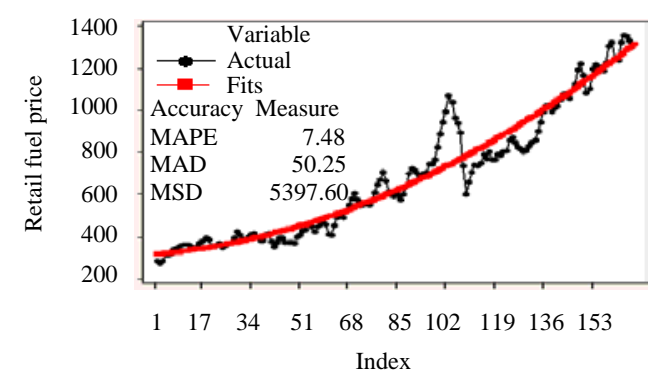

Fig. 2: Trend analysis plot of retail fuel price; (Quadratic trend model; $\mathrm{Yt}=316.1+1.201 * \mathrm{t}+0.02831 * \mathrm{t} * 2)$

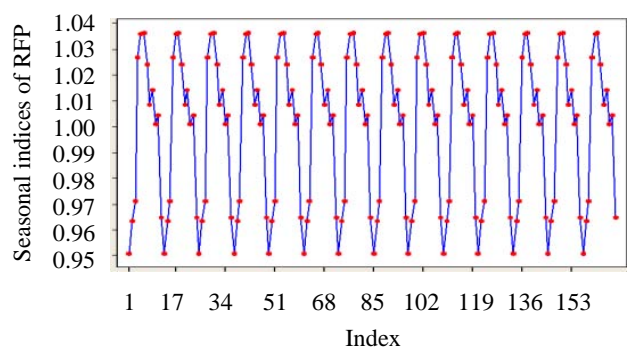

Fig. 3: Seasonal indices of retail fuel price
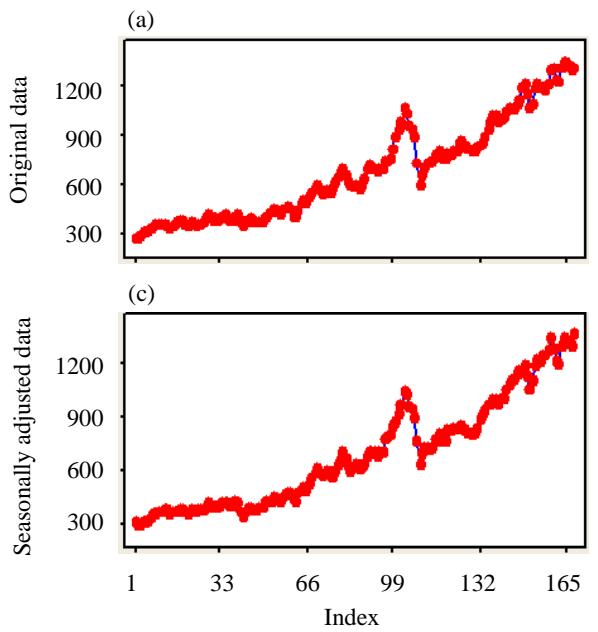

Retail fuel price series was detrended using the multiplicative model. That is dividing the RFP series by its corresponding trend values. Figure 4 is the graphical representation of the detrended data. It was observed from this figure that the detrended data of RFP have a constant peak which is an indication of being free from trend movement.

Investigating stationarity of the series: Stationarity of RFP series is investigated with the aid of correlogram which is the plot of autocorrelation function against lag $\mathrm{k}$. Figure 5 is the correlogram plot of RFP. It was observed from this plot that their respective ACF decay to zero as lag increases. And this implies that the RFP series is stationary.

Forecasting: Figure 6 is the plot of forecast RFP series together with its actual and fit series. It was observed from this plot that the past patterns of RFP series continue into the future forecast. The 5 years monthly forecast values of RFP are shown in appendix. These forecast values were obtained using the forecast model given below and this model is $92.52 \%$ scientifically reliable and efficient as obtained by MAPE. That is, this forecast is on average off by $7.48 \%$. Retail fuel price forecast model:

$$
F_{t}=316.1+1.201 t+0.02831 t^{2}, t=169,170, \ldots, 228
$$

Where:

$\mathrm{F}_{\mathrm{t}}$ : Forecast value at time $(\mathrm{t})$

$\mathrm{t}$ : Forecast period in month

The forecasts developed from the selected model appear in the appendix of this study. The quadratic trend model seems to provide the best fit among the models examined in the study. There is a clear increasing trend of
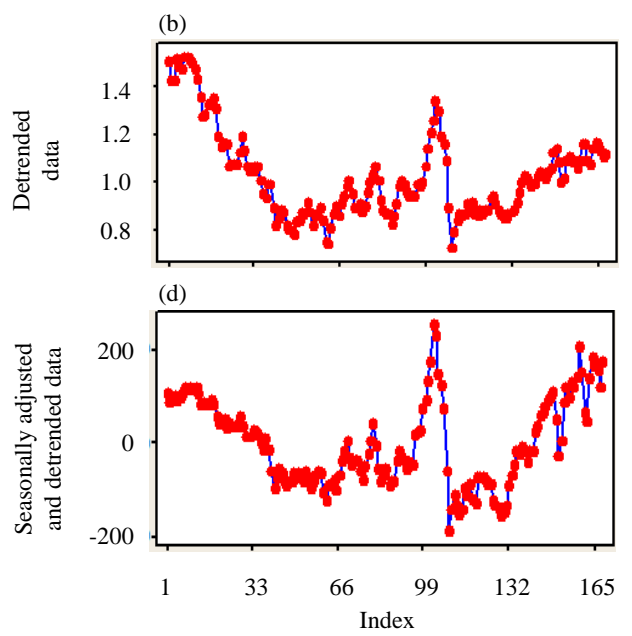

Fig. 4(a-d): Component analysis of retail fuel price (Multiplicative model) 


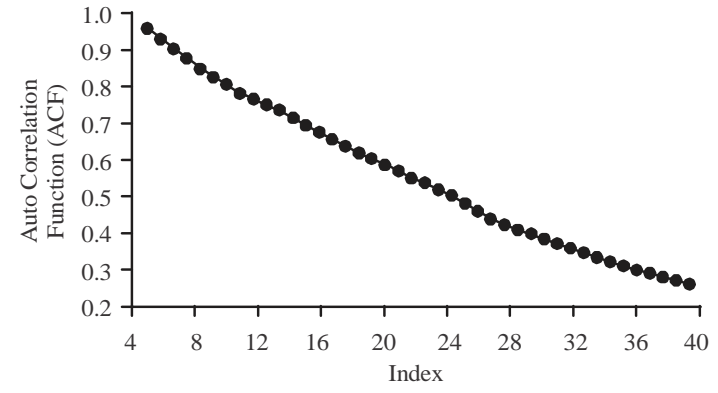

Fig. 5: Correlogram of retail fuel prices

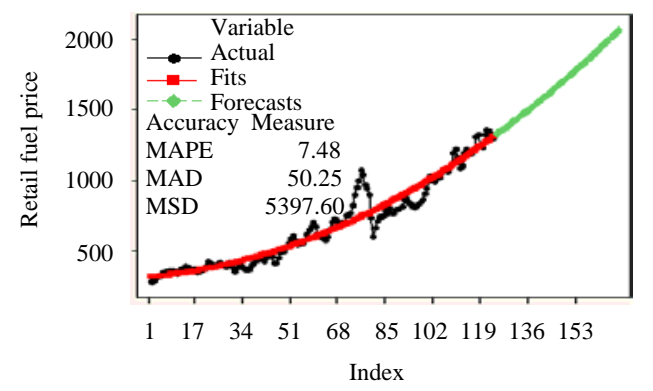

Fig. 6: Forecasts of retail fuel prices; (Quadratic trend model; $\mathrm{Yt}=316.1+1.201 * \mathrm{t}+0.02831 * t * * 2)$

petrol price. The trend started slowly in the first few years. Then latter it grew exponentially fast. The increasing trend in petrol price which is not always anticipated by the consumer, contributes to disposable cash reduction.

The other pattern of petrol price that the study revealed was seasonality. When the price of petrol price is high, seasonality is a pattern that indicates that the disposable income of consumer is reduced. Figure 3 shows that the petrol price seasonality for South Africa is too short, since, the trough is a point that turn upwards immediately after touching the ground.

Most of the time in this study, the South African petrol price is high. Thus, desirable patterns for ordinary consumers are low petrol price season and decreasing petrol price trend. However, these are the infrequent patterns revealed in the study.

The study shows that government revenue sourced from the price of petrol increases exponentially while consumer's disposable income gets frustrated due to unpredictability in increasing price patterns.

\section{CONCLUSION}

In RFP analysis, the study found that the past patterns of the series continue into the future. This was a confirmation of one of the two underlying assumption of time series. Hence, there would continually be increase in the future retail fuel price and fuel sales volume of petrol in South Africa. Furthermore, the forecast models used above are all statistically accurate and reliable as confirmed by the values of MAPE; MAD and MSD.

\section{ACKNOWLEDGEMENT}

The researchers acknowledge the opportunity granted by the Department of Statistics and Operations Research of the university.

\section{APPENDIX}

Appendix 1

\begin{tabular}{ll}
\hline Period & Forecast \\
\hline 169 & 1327.48 \\
170 & 1338.28 \\
171 & 1349.13 \\
172 & 1360.04 \\
173 & 1371.01 \\
174 & 1382.03 \\
175 & 1393.11 \\
176 & 1404.25 \\
177 & 1415.44 \\
178 & 1426.69 \\
179 & 1437.99 \\
180 & 1449.36 \\
181 & 1460.78 \\
182 & 1472.25 \\
183 & 1483.78 \\
184 & 1495.37 \\
185 & 1507.02 \\
186 & 1518.72 \\
187 & 1530.48 \\
188 & 1542.29 \\
189 & 1554.17 \\
190 & 1566.09 \\
191 & 1578.08 \\
192 & 1590.12 \\
193 & 1602.22 \\
194 & 1614.38 \\
195 & 1626.59 \\
196 & 1638.86 \\
197 & 1651.18 \\
198 & 1663.56 \\
199 & 1676.00 \\
200 & 1688.49 \\
201 & 1701.05 \\
202 & 1713.65 \\
203 & 1726.32 \\
204 & 1739.04 \\
205 & 1751.82 \\
206 & 1764.65 \\
207 & 1777.54 \\
208 & 1790.49 \\
209 & 1803.49 \\
210 & 1816.55 \\
211 & 1829.67 \\
212 & 1842.85 \\
213 & 1856.08 \\
214 & 1869.36 \\
215 & 1882.71 \\
216 & 1896.11 \\
217 & 1909.57 \\
218 & 1923.08 \\
219 & 1936.65 \\
220 & 1950.28 \\
221 & 1963.96 \\
223 & 1977.70 \\
224 & 1991.50 \\
225 & 2005.35 \\
226 & 2019.26 \\
\hline & 2033.23 \\
\hline & 2047.25 \\
23 & 2061.33 \\
\hline &
\end{tabular}




\section{REFERENCES}

Anonymous, 2008. Hydrogen and fuel cell technologies in South Africa. Department of Science and Technology, Pretoria, South Africa.

Anonymous, 2009. Policies, acts and legislations. Department of Energy, Pretoria, South African.

Armstrong, J.S., 2012. Illusions in regression analysis. Int. J. Forecasting, 28: 689-694.

Enders, W., 2003. WIE Applied Econometric Times Series (Wiley Series in Probability and Statistics). 2nd Edn., Wiley, New York, USA., ISBN: 9780471451730, Pages: 460.

Kantz, H. and T. Schreiber, 2004. Nonlinear Time Series Analysis. 2nd Edn., Cambridge University Press, London, UK., ISBN: 9780521529020, Pages: 369.

Lloyd, P., 2001. The South African petroleum industry: A review. The Automobile Association of South Africa, Sandton, South Africa.
Mondliwa, P. and S. Roberts, 2014. Review of economic regulation of liquid fuels and related products. Regulatory Entities Capacity Building Project, Centre for Competition, Regulation and Economic Development, University of Johannesburg, Johannesburg, South Africa. https://scholar. googleusercontent.com/scholar?q=cache:VZqA8C m8xG AJ:scholar.google.com/+R

Nikolic, D., R.C. Muresan, W. Feng and W. Singer, 2012. Scaled correlation analysis: A better way to compute a cross-correlogram. Eur. J. Neurosci., 35: 742-762.

Shasha, D.E. and Y. Zhu, 2004. High Performance Discovery in Time Series: Techniques and Case Studies. Springer, Berlin, Germany, ISBN: 9780387008578, Pages: 190.

South Africa, 2008. Annual Book of Petroleum Prices and Trends. Department of Science and Technology (DST), Pretoria, South Africa,.

Woodward, W.A., H.L. Gray and A.C. Elliott, 2011. Applied Time Series Analysis. CRC Press, Boca Raton, Florida, USA., ISBN: 9781439897690 , Pages: 564. 